\title{
Plateau Mountain Eco-Security Early Warning Research
}

\author{
Tingting Ma1, ${ }^{1,}$ Xiaolei Zhang ${ }^{1 *}$, Zhaoping Yang ${ }^{1}$, Fang Han', \\ Hui Shi', Cuirong Wang, ${ }^{1,2}$, Qun Liu', ${ }^{1,2}$
}

${ }^{1}$ Xinjiang Institute of Ecology and Geography, Chinese Academy of Sciences, Urumqi 830011, Xinjiang, China ${ }^{2}$ University of Chinese Academy of Sciences, Beijing 100039, China

Received: 11 December 2015

Accepted: 2 February 2016

\begin{abstract}
At present, overseas and domestic eco-security early warning research is in the exploratory stage. This paper uses Kizilsu Kirghiz Autonomous Prefecture as the research object and constructs an evaluation index system based on the pressure-state-response (P-S-R) conceptual model. This study analyzes eco-security early warning in the study area using the granger causality test model, the entropy weight method, and the matter-element model, and analyzes the present eco-security situation and future development trends in the study area. The author hopes that this study can further enrich eco-security early warning research and provide a scientific reference for ecological security in the study area. The specific research results were as follows:

1) This article evaluated the plateau mountain ecological security early warning system, and the application of the Granger causality test was further implemented with targeted and objective index system selection, achieving a one-to-one analysis in the results and further enriching the research theory of the importance of eco-security early warning systems.

2) On the whole, the eco-security situation in the study area is gradually moving in a positive direction, but the low level of overall eco-security continues to cause great pressure.

3) From 2005 to 2014, the study area gradually attached greater importance to the construction of ecosecurity, but the overall eco-security level is low, and the overall eco-security regulation capacity is insufficient.

4) The key eco-security pressure in the study area mainly derives from industrial and agricultural development, although the control power is gradually increasing, but the control effect is not obvious, and the contradiction between ecological security and socio-economic development is still very obvious.

5) The study area is a typical earthquake-prone area, and financial input into the governance of natural geological disasters due to the high frequency of earthquakes is gradually increasing; but the study area still needs to increase its investments.
\end{abstract}

Keywords: plateau mountain, eco-security early warning, granger causality test model, matter-element model 


\section{Introduction}

Ecological security is a concept that was first proposed by the United States government [1]. Eco-security early warning systems are an important part of eco-security, and predictability is a characteristic feature of eco-security early warning. At present, although eco-security early warning research is still in the exploration stage, overseas and domestic scholars have achieved results in this area. Overseas scholars have performed many studies in climate and ecosystem shock prediction [2], natural disaster advanced warning [3-8], environmental health assessment [9], eco-environmental evolution [10], ecosystem function [11], and ecosystem stability [12], etc. Domestic scholars have performed many studies in ecological security mechanisms, theoretical study, early-warning models [13], etc., involving cities, landscape ecology, heritage sites, agriculture, soil, hydrology, and many other aspects [13-18].

Current research methods of eco-security early warning research primarily include the fuzzy comprehensive evaluation method, artificial neural networks, the Delphi method, the Markov prediction method, ecological footprinting, 3S, etc. [7, 13, 15-16, 19-24]. Due to the complexity of the research question, this paper chose the matter-element model, which was proposed by the Chinese scholar Cai Wen in 1994; he explains the process of the matter-element model analysis and complex problems in his book, The Matter-Element Model and Its Application.
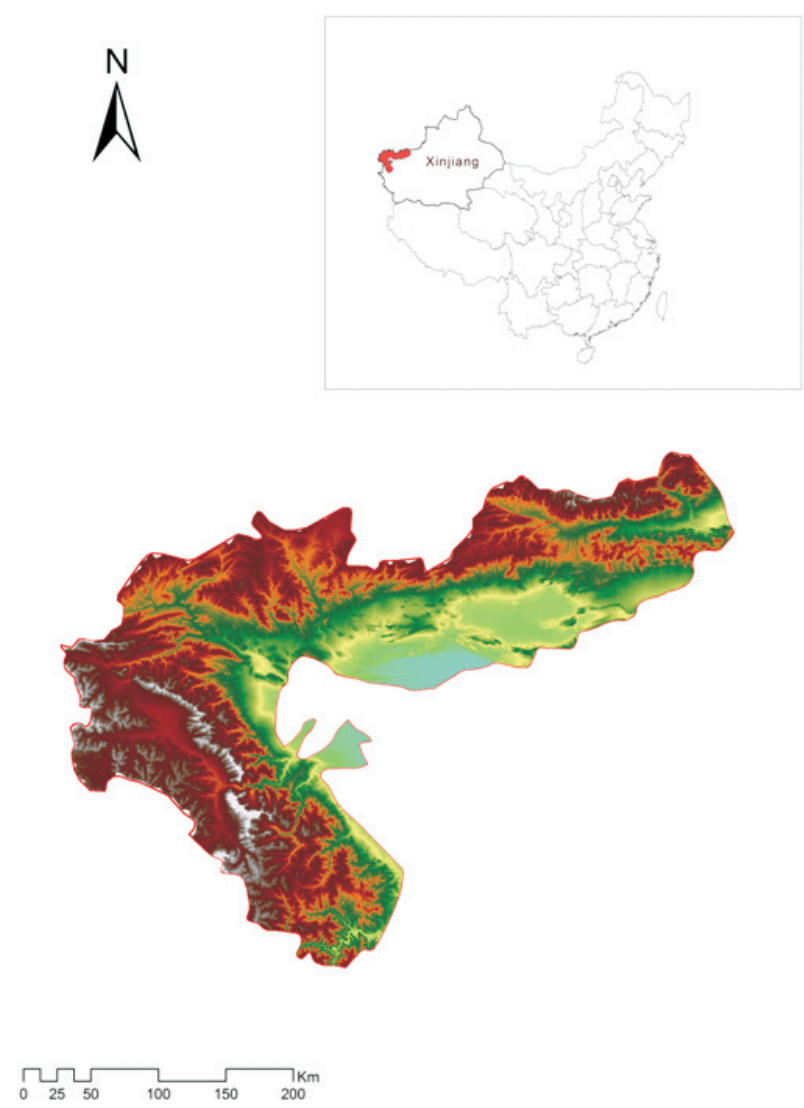

Fig. 1. The study area of Kizilsu Kirghiz Autonomous Prefecture.
He notes that the matter-element model is a type of human brain model focusing on how to address contradiction issues [25]. At present, this method has been used in ecological environment assessment, disaster forecasting, etc., and it has been proven to have reliable predictability when dealing with complex issues [15, 26-27].

In an actual analysis, choosing indicators affects the outcome among many already selected indicators and further overcomes the subjectivity of expert consultation; this is the problem in the research of early warning because previous studies about this topic are very limited. The most common methods are principal component analysis (PCA) or filtering by index weight [28-30]. However, these methods still cannot achieve a targeted one-to-one analysis. To further improve the pertinence and objectivity of index selection, the author cites the granger causality test model. It was proposed by Granger in 1969 and is widely used to ascertain the importance of the interaction between two series [31]. At present, this method is widely used in economics and energy fields [31-34]; our analysis applied this method to ecological security warning, and the author hopes that through the application of this method, the scientific nature of the index selection can be improved and theoretical research can be enriched.

Mountain ecological systems are unique, have the feature of vulnerability and exhibit sensitivity to external forces and susceptibility to mountain disasters [35-36]. However, mountain eco-security early warning research is very limited overseas, and domestically the common research topic is mountain city ecological security evaluation [1, 37], mountain hazards monitoring and management [38-40], the sustainable development of mountain social ecosystems [41-42], mountain grassland characteristics and threats research [43-44], mountain forest ecosystem species distribution and composition, disaster prevention and management research [45-48], and mountain soil research [49], etc.

Based on the plateau mountain ecological security research perspective, this paper conducts plateau mountain ecological security early warning research using the Granger causality test model method, the matterelement model and the entropy weight method. We hope this study will enrich and improve mountain ecological security research. At the same time, the results could provide scientific guidance for local ecological sustainable development.

\section{Study Area}

Kizilsu Kirghiz Autonomous Prefecture is located in western Xinjiang, China, in the high mountains and lofty hills of the Kunlun Mountains and the western Tianshan Mountains. To the southeast is the edge oasis of Tarim Basin and Kashgar Plain, and to the north and northwest are the Tianshan and Pamirs mountain ranges. The total area is 7.25 square kilometers, and within mountain territory, the landscape is extremely complex and the mountainous area occupies more than $90 \%$ of the total (Fig.1). 
The study area is located at the mid-latitudes, but far from the sea, and belongs to a typical temperate continental climate with a lack of rain, sufficient sunlight on the plains, and variable temperatures in the spring and autumn [50]. From 2005 to 2014, the study area experienced fast economic growth, and the average growth rate was $12.9 \%$. The study area belongs to an ecologically sensitive area with low biomass, simple system structure, poor coordination, weak ecological function, easily damaged and difficult-to-restore ecology, and an environment facing the dual impacts of human society and the natural environment, where geological disasters occur frequently.

\section{Data and Methodology}

\section{Data Collection}

The main data source for this study was the Xinjiang statistical yearbook (2005-14), a statistical bulletin for national economic and social development of the Kizilsu Kirghiz Autonomous Prefecture (2005-14), the Kizilsu Kirghiz Autonomous Prefecture environmental bulletin, Kizilsu Kirghiz Autonomous Prefecture urban planning system (2013), CNKI, China's system for macro data mining analysis (http://number.cnki.net/cyfd/), the general land use plan of the Kizilsu Kirghiz Autonomous Prefecture (2010-20), the main pollution control plan of the Kizilsu Kirghiz Autonomous Prefecture (2015), and China's earthquake administration department ( http:// www.cea.gov.cn/). We obtained the missing data for an individual year through a trend extrapolation method.

\section{PSR Conceptual Model for a Plateau-Mountain Eco-Security Index}

Construction of an ecological security warning index system is the basis for the establishment of a warning mechanism [19], The "pressure-state-response" conceptual model was proposed by the United Nations Environment Program (UNEP) and has been widely used $[23,51]$. The research incorporates relevant research $[13,15,36,40$, 52-54] and combines plateau-mountain environmental features in the study area. We constructed a PSC conceptual model for a plateau-mountain eco-security index. Based on considerations of available data and continuity, and through expert consultation, an evaluation index of the study area was established and is shown in Table 1.

\section{Granger Causality}

The Granger causality test could help improve the predictability of present and future estimations in another time series [55-56]. The first step of the Granger causality is a stationary test (ADF). However, the series requires a Johansen cointegration test when the series is nonstationary, and Granger causality can be used through the JCT test.
The $X 2$ causes are defined as X1 if the inclusion of past observations of $X 2$ in a regression model reduces the prediction error of $X 1$ compared to a model without $X 2$ information.

For two time series, $X 1(t)$ and $X 2(t)$, from two stationary stochastic processes, a bivariate autoregressive (AR) model can be built as follows:

$$
\begin{gathered}
X 1(t)=\sum_{i=1}^{m} \alpha i X_{t-i}+\sum_{i=1}^{m} \beta i Y_{t-i}+\mu_{1 t} \\
X 2(t)=\sum_{i=1}^{m} \lambda i Y_{t-i}+\sum_{i=1}^{m} \delta i X_{t-i}+\mu_{2 t}
\end{gathered}
$$

$\ldots$ where $\boldsymbol{\alpha} \boldsymbol{i}, \boldsymbol{\beta} \boldsymbol{i}, \boldsymbol{\lambda} \boldsymbol{i}, \boldsymbol{\delta} \boldsymbol{i}$ are the AR coefficients, $\boldsymbol{\mu}_{1 t}$ and $\boldsymbol{\mu}_{2 t}$ are the prediction errors or residuals of the model, and $\boldsymbol{m}$ is the model order that defines how many time lags are included in the regression model equations.

The F-test is the core of the Granger causality test, and the hypothesis is that $\mathrm{X}^{\prime}$ is not the Granger cause of $\mathrm{Y}^{\prime}$ if the $\mathrm{F}$ value is greater than the critical value $\mathrm{F}_{\alpha}$ under a significance level of $\boldsymbol{\alpha}$, or else rejects the null hypothesis.

If $\mathrm{X}$ and $\mathrm{Y}$ do not involve co-integration under the integrated order, the Granger causality analysis can be preceded by the first order difference method:

$$
\begin{aligned}
& Y t=\sum_{i=1}^{m} \alpha i \Delta X_{t-i}+\sum_{i=1}^{m} \beta i \Delta Y_{t-i}+\mu_{1 t} \\
& X t=\sum_{i=1}^{m} \lambda i \Delta Y_{t-i}+\sum_{i=1}^{m} \delta i \Delta X_{t-i}+\mu_{2 t}
\end{aligned}
$$

Define $\Delta \boldsymbol{X}_{t-i}, \boldsymbol{Y}_{t-i}$ as the value of $\boldsymbol{X}, \boldsymbol{Y}$ under the first order difference sequence where the lag value is $\boldsymbol{i}$. At present, we can use Eviews 6.0 to undertake the Granger causality test.

\section{Membership Functions}

For the overall sample, how to further analyze which factors should be selected and which should be deleted based on the results of the Granger causality test is a key link for the index weight and the matter-element model analysis. This article proceeds with the next analysis based on the fuzzy sets idea proposed by the cybernetics professor L. A. Zadeh (1969) [57] and the combined membership functions. At present, there has been no unified membership function according to the characteristics of data sampling, and the study cites the membership function in Wang's membership function research as

$$
K=n_{i} / N
$$

...where $\boldsymbol{n}_{\mathrm{i}}$ is the frequency of $\boldsymbol{v}_{\boldsymbol{\theta}} \in \boldsymbol{A}, \boldsymbol{A}$ is the fuzzy set, and $\boldsymbol{N}$ is the total test [58].

\section{Entropy Method for Index Weights}

The key issue in evaluating ecological security (ES) from the indicators was how to weigh each indicator with minimal subjectivity [51]. Claude Elwood Shannon put 
Table 1. Evaluation index based on the PSR.

\begin{tabular}{|c|c|c|}
\hline Project layer & Index layer & Unit \\
\hline \multirow{20}{*}{ Pressure layer } & $\mathrm{X} 1$ : grade 5 or above earthquake frequency per year & time \\
\hline & $\mathrm{X} 2$ : GDP growth rate & $\%$ \\
\hline & X3: natural population growth rate & $\%$ \\
\hline & $\mathrm{X} 4$ : construction land area & $\times 10^{4} \cdot \mathrm{hm}^{-2}$ \\
\hline & X5: total water use growth rate per year & $\%$ \\
\hline & X6: water consumption per capita & $\mathrm{m}^{3}$ \\
\hline & $\mathrm{X} 7$ : industry power consumption & $\mathrm{kWh} /$ per year \\
\hline & X8: the amount of plastic mulch usage & $\mathrm{t}$ \\
\hline & X9: agriculture power consumption & $\mathrm{kWh} /$ per year \\
\hline & $\mathrm{X} 10$ : industrial wastewater emissions & $\times 10^{4} \mathrm{t}$ \\
\hline & X11: industrial waste gas emissions & $\times 10^{9} \mathrm{~m} 3$ \\
\hline & $\mathrm{X} 12$ : industrial $\mathrm{SO}_{2}$ emissions & $\mathrm{t}$ \\
\hline & X13: domestic sewage emissions & $\times 10^{4} \mathrm{t}$ \\
\hline & X14: building construction area & $\times 10^{4} \mathrm{~m}^{2}$ \\
\hline & X15: wood harvesting & $\mathrm{m}^{3}$ \\
\hline & X16: industrial soot emissions & $\mathrm{t}$ \\
\hline & $\mathrm{X} 17$ : industrial dust emissions & $\mathrm{t}$ \\
\hline & X18: solid waste emissions & $\mathrm{t}$ \\
\hline & X19: the amount of chemical fertilizer usage & $\mathrm{t}$ \\
\hline & $\mathrm{X} 2:$ the amount of sheep & $\times 10^{4}$ head \\
\hline \multirow{11}{*}{ State layer } & $\begin{array}{c}\text { Y1: the amount of rural people who achieve a standard of drinking } \\
\text { water quality }\end{array}$ & $\times 10^{4}$ \\
\hline & Y2: grass area & ha \\
\hline & Y3: average annual precipitation & $\mathrm{mm}$ \\
\hline & Y4: drought area & ha \\
\hline & Y5: flood area & ha \\
\hline & Y6: annual sunshine duration & $\mathrm{h}$ \\
\hline & Y7: mean annual temperature & ${ }^{\circ} \mathrm{C}$ \\
\hline & Y8: days of good air environment quality & day \\
\hline & Y9: green areas rate of built-up area & $\%$ \\
\hline & Y10: rate of pest and disease damage prevention & $\%$ \\
\hline & Y11: treatment rate of urban effluent & $\%$ \\
\hline \multirow{5}{*}{ Control layer } & $\mathrm{Z1}$ : collection of books & ben/ per 10,000 people \\
\hline & Z2: water loss and soil erosion control area & $\times 10^{3} \mathrm{ha}$ \\
\hline & Z3: reforested area & ha \\
\hline & Z4: the number of schools & suo \\
\hline & Z5: the fund for geological disaster prevention & $\times 10^{4} \mathrm{RMB}$ \\
\hline
\end{tabular}


forward the concept of entropy and introduced information theory [59]. The entropy method is a mathematical method for calculating the index weight that is based on the comprehensive consideration of various factors that entropy information provides, and it has been widely used $[28,51,60]$.

This approach assumes that the number of eco-security evaluation indexes of the evaluation object is $\boldsymbol{m}$; they are $\boldsymbol{X I}(i=1,2,3 \ldots, \mathrm{m})$ and we obtained the statistics for each indicator, assuming the matrix is $\mathrm{R}^{\prime}=\left(\mathrm{r}_{i j}{ }^{\prime}\right)_{m \times n}(i=1,2, \ldots, \mathrm{m}$ $\mathrm{j}=1,2, \ldots, \mathrm{n})$, defining $\boldsymbol{r}_{i j}$ as the statistics of a certain index in a particular year. To eliminate the influence of different units for the indicators, the paper used the extremum method according to Eq. (6) to standardize the matrix $\mathrm{R}^{\prime}$ and obtain the standardization matrix $\mathbf{R}$. This approach assumes the standardization matrix $\mathbf{R}^{\prime}=\left(\mathrm{r}_{i j}\right)_{m \times n}$, and the standardization function is as follows:

$$
r_{i j}=\frac{r_{i j}^{\prime}-\min \left|r_{i j}^{\prime}\right|}{\max \left|r_{i j}^{\prime}\right|-\min \left|r_{i j}^{\prime}\right|} \times 10
$$

The entropy of the index $\boldsymbol{i}$ is defined as follows:

$$
H_{i}=-\mathrm{K} \sum_{j=1}^{n} f_{i j} \ln f_{i j}
$$

... where the $f_{\mathrm{ij}}=\frac{r_{\mathrm{ij}}}{\sum_{j=1}^{n} r_{\mathrm{ij}}}, \mathrm{k}=\frac{1}{\ln n}\left(\right.$ If $\left.f_{\mathrm{ij}}=0, f_{\mathrm{ij}} \ln f_{\mathrm{ij}}=0\right)$

... then we can calculate the entropy weights of each index with the following function (8).

$$
W_{i}=\frac{1-H_{i}}{m-\sum_{i=1}^{m} H_{i}}
$$

\section{Matter-Element Model}

The specific steps are as follows:

1) Determine the matter-element matrix, classic domain matter-element matrix, and joint domain matter-element matrix.

This assumes that the ecological security levels are $N_{1}$, $N_{2}, \ldots \ldots, N_{m}$, and establishes the matter-element matrix $R_{j}$

$R_{j}=\left(\left(N_{j}, c_{i}, v_{j i}\right)\right)=\left[\begin{array}{ccc}N_{j} & c_{1} & v_{j 1} \\ & c_{2} & v_{j 2} \\ & \ldots & \ldots \\ & c_{n} & v_{j n}\end{array}\right]=\left[\begin{array}{ccc}N_{j} & c_{1} & <a_{j 1}, b_{j 1}> \\ & c_{2} & <a_{j 2}, b_{j 2}> \\ \ldots & \ldots \\ & c_{n} & <a_{j n}, b_{j n}>\end{array}\right]$

$R_{j}$ is defined as the classic domain matter-element matrix of ecological security; $N_{j}$ is the ecological security level $(\mathrm{j}=1,2, \ldots \mathrm{m})$; ci $(\mathrm{i}=1,2, \ldots \mathrm{n})$ is the characteristic of ecological security at level $N_{j} ; v_{j i}$ is the stipulated value range of the $N_{j}$ on $c_{i}$, which is the data range of the ecological security level corresponding to their characteristics. Next, the joint domain matter-element matrix $R_{p}$ is constructed:

$$
R_{p}=\left(\left(N_{p}, c_{i}, v_{i p}\right)\right)=\left[\begin{array}{ccc}
N_{p} & c_{1} & v_{1 p} \\
& c_{2} & v_{2 p} \\
& \ldots & \ldots \\
& c_{n} & v_{n p}
\end{array}\right]=\left[\begin{array}{ccc}
N_{j} & c_{1} & <a_{1 p}, b_{1 p}> \\
c_{2} & <a_{2 p}, b_{2 p}> \\
\ldots & \ldots \\
c_{n} & <a_{n p}, b_{n p}>
\end{array}\right]
$$

$\ldots$ where $N_{p}$ is the total ecological security level and $v_{i p}$ is the data range of $N_{p}$ about $c_{i}$.

For the early warning object, the early warning index matter-element matrix is $R_{o}$ :

$$
R_{o}=\left(\left(N_{o}, c_{i}, v_{i}\right)\right)=\left[\begin{array}{ccc}
N_{o} & c_{1} & v_{1 p} \\
& c_{2} & v_{2 p} \\
\ldots & \cdots \\
& c_{n} & v_{n p}
\end{array}\right]
$$

...where $N_{o}$ is defined as the name of the early warning object and $v_{i}$ is the data range of $N_{o}$ about $c_{i}$.

2) Determine the correlation function and correlative degree. The correlative degree of each ecological security is calculated according to the correlative degree function (12):

$\mathrm{K}\left(v_{i}\right)=\left\{\begin{array}{l}\frac{\rho\left(v_{i}, V_{i j}\right)}{\rho\left(v_{i}, V_{i p}\right)-\rho\left(v_{i}, V_{i j}\right)}, \rho\left(v_{i}, V_{i p}\right)-\rho\left(v_{i}, V_{i j}\right) \neq 0 \\ \rho\left(v_{i}, V_{i j}\right)-1, \rho\left(v_{i}, V_{i p}\right)-\rho\left(v_{i}, V_{i j}\right)=0\end{array}\right.$

The $\mathrm{K}\left(v_{i}\right)$ is the correlative degree of each ecological security index about the security levels, where is the distance between point $\rho\left(v_{i}, V_{i j}\right)$ and the finite interval of its corresponding eigenvectors $\left(a_{i j}, b_{i j}\right) ; \rho\left(v_{i}, V_{i p}\right)$ is the distance between point $v_{i}$ and the joint domain of its corresponding eigenvectors $\left(a_{i p}, b_{i p}\right) ; v_{i}$ is the actual value of the index; $V_{i j}$ is the classic domain matter-element matrix; $V_{i p}$ is the joint domain matter-element matrix; and

$$
\rho(x,<\mathrm{a}, \mathrm{b}>)=\left|x-\frac{a+b}{2}\right|-\frac{b-\mathrm{a}}{2}
$$

\section{3) Evaluate the security level.}

The value of the correlative degree function $\mathrm{K}\left(v_{i}\right)$ indicates the membership degree to which the early warning object $R_{o}$ meets the ecological security levels. The correlative degree of the early warning object about the security levels $j$ is as follows:

$$
\mathrm{K}_{j}\left(\mathrm{R}_{o}\right)=\sum_{i=1}^{n} \mathrm{w}_{j i} \mathrm{~K}_{j}\left(\mathrm{v}_{i}\right)
$$

If $\mathrm{K}_{j o}={ }_{j \in[1,2, \ldots, \mathrm{m}]} \mathrm{K}_{j}\left(\mathrm{R}_{o}\right)$, the $R_{o}$ belongs to security level $\mathrm{j}_{o}$ when $\mathrm{K}_{j}\left(R_{o}\right)>0$, the early warning object matches some security level, and the greater the value, the better the met degree; when $-1 \leq \mathrm{K}_{j}\left(R_{o}\right) \leq 0$, the early warning object does not match a security level, but it has the condition to turn into this security level, and the greater 
the value, the easier the transformation; when $\mathrm{K}_{j}\left(R_{o}\right)-1$, the early warning object does not match a security level, and it has no condition to this security level; the smaller the value, the easier the transformation, and the greater the gap to match some security level.

\section{Results}

\section{Selection Analysis Based on} the Eco-Security Index

For the index selection analysis, this paper used the Granger causality test model to perform a one-to-one correspondence causal relationship analysis based on the pressure and state layer index from expert consultation. The aim was to overcome the subjectivity of index system selection, to determine the real factors affecting ecological security, to avoid unnecessary analysis, and to improve pertinence and efficiency. The study used Eview 6.0 to do the Granger causality analysis. The results of the Eviews 6.0 analysis are shown in Table 2 (' 0 ' means $\mathrm{X}_{i}$ is not the Granger cause of $\mathrm{Y}_{i}$, ' 1 'means $\mathrm{X}_{i}$ is the Granger cause of $\left.\mathrm{Y}_{i}\right)$.
We can obtain the results where each $\mathrm{Y}_{i}$ is caused by a reason $X_{i}$ from Table 2 . For the total analysis, we calculated the membership of each factor by a membership function (5); however, we need to clearly note whether the $\mathrm{X}_{i}$ is the reason for $\mathrm{Y}$. Therefore, the division of the value interval is essential, according to a consultation of relevant ecology experts, local environmental professionals in the study area, and a characteristics analysis of the study area; the scope $[0,1]$ is divided into four intervals: extremely not belonging to $\mathrm{X}_{i}, 0 \leq \mathrm{X}<0.25(\mathrm{EN})$; not belonging to $\mathrm{X}_{i}, 0.25 \leq \mathrm{X}<0.5(\mathrm{~N})$; belonging to $\mathrm{X}_{i}, 0.5 \leq \mathrm{X}<0.75(\mathrm{Y})$; and extremely belonging to $\mathrm{X}_{i}, 0.75 \leq \mathrm{X} \leq 1$ (EY). The results are shown in Table 3.

From Table 3, the actual reasons that affect the $\mathrm{Y}_{i}$ are X1, X3, X4, X5, X6, X7, X8, X9, X10, X13, X14, X15, $\mathrm{X} 16, \mathrm{X} 18$, and X19.

\section{Eco-Security Early Warning Grade and Index Weight}

The combined concept of plateau mountainous ecological security that the author puts forward in this paper, according to the degree of eco-security, indicates that eco-security early warning could be divided into the

Table 2. The results of Granger analysis.

\begin{tabular}{|c|c|c|c|c|c|c|c|c|c|c|c|c|}
\hline \multicolumn{13}{|c|}{ Results of the Granger analysis } \\
\hline & Y1 & Y2 & Y3 & Y4 & Y5 & Y6 & Y7 & Y8 & Y9 & Y10 & Y11 & $\mathrm{n}_{i}$ \\
\hline $\mathrm{X} 1$ & 0 & 0 & 1 & 1 & 1 & 0 & 1 & 0 & 0 & 1 & 1 & 6 \\
\hline $\mathrm{X} 2$ & 0 & 1 & 1 & 0 & 0 & 0 & 1 & 1 & 1 & 0 & 1 & 3 \\
\hline X3 & 0 & 0 & 1 & 0 & 0 & 1 & 1 & 0 & 0 & 0 & 0 & 6 \\
\hline X4 & 1 & 0 & 1 & 0 & 0 & 0 & 1 & 0 & 1 & 1 & 1 & 6 \\
\hline X5 & 1 & 0 & 1 & 1 & 1 & 0 & 0 & 1 & 1 & 1 & 0 & 7 \\
\hline X6 & 1 & 1 & 0 & 1 & 0 & 1 & 1 & 0 & 1 & 0 & 1 & 7 \\
\hline $\mathrm{X} 7$ & 1 & 0 & 0 & 0 & 1 & 0 & 1 & 1 & 0 & 1 & 1 & 6 \\
\hline X8 & 1 & 0 & 1 & 0 & 1 & 1 & 1 & 0 & 1 & 0 & 1 & 7 \\
\hline X9 & 1 & 1 & 0 & 1 & 0 & 1 & 1 & 0 & 0 & 0 & 1 & 6 \\
\hline $\mathrm{X} 10$ & 1 & 0 & 0 & 1 & 0 & 1 & 1 & 0 & 1 & 0 & 1 & 6 \\
\hline $\mathrm{X} 11$ & 1 & 0 & 0 & 0 & 1 & 0 & 1 & 0 & 1 & 0 & 1 & 5 \\
\hline $\mathrm{X} 12$ & 0 & 1 & 0 & 0 & 1 & 1 & 0 & 0 & 1 & 0 & 0 & 4 \\
\hline X13 & 1 & 0 & 1 & 0 & 0 & 1 & 1 & 0 & 1 & 1 & 1 & 7 \\
\hline X14 & 0 & 0 & 0 & 1 & 1 & 1 & 1 & 1 & 1 & 1 & 1 & 8 \\
\hline X15 & 0 & 1 & 1 & 0 & 0 & 0 & 1 & 1 & 0 & 1 & 1 & 6 \\
\hline X16 & 1 & 0 & 0 & 1 & 0 & 0 & 1 & 1 & 0 & 1 & 1 & 6 \\
\hline X17 & 0 & 0 & 0 & 0 & 0 & 1 & 1 & 0 & 0 & 0 & 1 & 3 \\
\hline X18 & 1 & 1 & 0 & 0 & 1 & 0 & 0 & 1 & 0 & 1 & 1 & 6 \\
\hline X19 & 1 & 0 & 0 & 0 & 1 & 1 & 1 & 1 & 1 & 0 & 1 & 7 \\
\hline X 20 & 1 & 0 & 0 & 0 & 0 & 0 & 0 & 0 & 0 & 0 & 1 & 2 \\
\hline
\end{tabular}


following categories: no warning (NW - safe), forewarning (FW - relatively safe), middle warning ( $\mathrm{MW}$ - will not be safe), light warning (LW - unsafe), heavy warning (HW - very unsafe), and these are matched with the colors of green, blue, yellow, orange, and red, respectively, to be visually displayed (Table 4).

The evaluation classification standards of each of the early warning indicators mainly refer to national and industry standards, regional planning, regional ecological environmental characteristics, overall regional development, and an analogy of the standard; we calculated each index weight through the functions (6), (7), and (8), and the results are shown in Table 5.

\section{Overall Analysis of Eco-Security Early Warning System in the Study Area}

As seen in Table 6, the ecological security status indicates a trend of fluctuations in the study area from 2005-14: heavy warnings in 2005 and 2007; light warnings in 2006 and 2014; middle warnings for 2008, 2009, and 2013; and 2008, 2010, 2011, and 2012 belong to the early warning or no warning categories. Although development in the study area fluctuated during the decade, the general development direction is positive in the future.

\section{Single Index Analysis}

To be able to apply eco-security factor analysis clearly, this research sets the middle, light, and heavy warnings as the warning sources that require special attention. In Table 7, the pressure on ecological security system in the study area is shown to be the strongest in 2014, and the sensitivity index rate is $38.7 \%$. The state of the ecological layer also shows an increasing sensitivity index trend.
From the control layer, the level of regulation and control ability did not change significantly compared with 2005 , and there was a declining trend from 2010-13.

Further analysis indicates the variation trend and the safety status of the warning indicators in the study area from 2005-14. We conducted a comparative analysis of the pressure layer in 2005 and 2014, and in Table 8 we can see that the indicators in 2005 that remain at the sensitive level are as follows: X3, X5, X6, X8, X15, X19; the indicators in 2014 that stay at the sensitive level are as follows: X3, X4, X5, X6, X7, X8, X9, X10, X15, X16, X18, and $\mathrm{X} 19$.

The level of overall economic development in the study area is low, the overall ecological security situation in 2005 is superior to 2014. From the pressure layer, the number of indicators in 2005 remaining at the no warning or forewarning are as follows: $\mathrm{X} 1, \mathrm{X} 4, \mathrm{X} 7, \mathrm{X} 9$, X10, X13, X14, X16, and X18. However, in 2014, six of the nine factors turned into middle, light, and heavy warnings, as follows: $\mathrm{X} 4, \mathrm{X} 7, \mathrm{X} 9, \mathrm{X} 10, \mathrm{X} 16$, and X18, and the development trend for five of them was positive; these included the following: X1, X4, X10, X16, X18. As seen in Table 8 , on the whole, the factors with a positive change trend are X1, X3, X4, X5, X10, X15, X16, X18, and X19. For five of them (X4, X10, X16, X18, and X19) compared with 2004, the warning level's difference is 2-3 grades different, e.g., in 2005, the X10, X16, and X18 remained at no warning or forewarning (although these factors' variation trend was positive in 2014, the warning grade was orange-light warning or red-heavy warning). From the state layer (Table 9), comparing 2005 with 2014, the warning source indexes indicated an increasing trend in the five warning source indexes (Y1, Y3, Y5, Y7, and Y9) and in 2005 increased to six in 2014: Y3, Y4, Y7, Y8, Y9, and Y10.

Table 3. The results of the selection analysis for eco-security indexes.

\begin{tabular}{|c|c|c|c|c|c|c|c|c|c|c|c|c|c|c|c|c|c|c|c|c|}
\hline $\mathrm{X}_{i}$ & $\mathrm{X} 1$ & $\mathrm{X} 2$ & $\mathrm{X} 3$ & $\mathrm{X} 4$ & $\mathrm{X} 5$ & $\mathrm{X} 6$ & $\mathrm{X} 7$ & $\mathrm{X} 8$ & $\mathrm{X} 9$ & $\mathrm{X} 10$ & $\mathrm{X} 11$ & $\mathrm{X} 12$ & $\mathrm{X} 13$ & $\mathrm{X} 14$ & $\mathrm{X} 15$ & $\mathrm{X} 16$ & $\mathrm{X} 17$ & $\mathrm{X} 18$ & $\mathrm{X} 19$ & $\mathrm{X} 20$ \\
\hline $\mathrm{n}_{i}$ & 6 & 3 & 6 & 6 & 7 & 7 & 6 & 7 & 6 & 6 & 5 & 4 & 7 & 8 & 6 & 6 & 3 & 6 & 7 & 2 \\
\hline $\mathrm{K}_{i}$ & 0.55 & 0.27 & 0.55 & 0.55 & 0.64 & 0.67 & 0.55 & 0.67 & 0.55 & 0.55 & 0.45 & 0.36 & 0.64 & 0.73 & 0.55 & 0.55 & 0.27 & 0.55 & 0.67 & 0.18 \\
\hline Result & $\mathrm{Y}$ & $\mathrm{N}$ & $\mathrm{Y}$ & $\mathrm{Y}$ & $\mathrm{Y}$ & $\mathrm{Y}$ & $\mathrm{Y}$ & $\mathrm{Y}$ & $\mathrm{Y}$ & $\mathrm{Y}$ & $\mathrm{N}$ & $\mathrm{N}$ & $\mathrm{Y}$ & $\mathrm{Y}$ & $\mathrm{Y}$ & $\mathrm{Y}$ & $\mathrm{N}$ & $\mathrm{Y}$ & $\mathrm{Y}$ & $\mathrm{EN}$ \\
\hline
\end{tabular}

Table 4 . The features of each eco-security early warning rank.

\begin{tabular}{|c|c|}
\hline Waning grade & State of ecological security classification \\
\hline NW (Green) & $\begin{array}{l}\text { the ecosystem service function is basically intact, the system recovery and regenerated ability is strong, natural and } \\
\text { man-made destructive effects are rare }\end{array}$ \\
\hline FW (Blue) & $\begin{array}{c}\text { the ecosystem service function is basically intact, it can recover from general disturbance, natural and man-made } \\
\text { damaging effects are less }\end{array}$ \\
\hline MW (Yellow) & $\begin{array}{l}\text { eco-security shows a negative development direction, the sensitivity of ecosystems are heightened and easily } \\
\text { deteriorate, natural and man-made destructive effects occur occasionally }\end{array}$ \\
\hline LW (Orange) & $\begin{array}{l}\text { the ecosystem function is seriously deteriorated, the function is seriously degenerated, ecosystem recovery is } \\
\text { difficult after disturbance, more natural and man-made destructive effects occur }\end{array}$ \\
\hline HW (Red) & $\begin{array}{l}\text { the ecosystem function has deteriorated, ecological self-recovery capability has been damaged severely, it is } \\
\text { extremely difficult to recover after disturbance, natural and man-made destructive impacts occur frequently }\end{array}$ \\
\hline
\end{tabular}


Table 5. Early warning standards of ecological security in Kizilsu Kirghiz Autonomous Prefecture.

\begin{tabular}{|c|c|c|c|c|c|c|c|}
\hline Project layer & Index layer & Index weights & NW & FW & MW & LW & HW \\
\hline \multirow{15}{*}{ Pressure layer } & $\mathrm{X} 1$ & 0.03862 & 0 & 1 & 2 & 3 & 4 \\
\hline & $\mathrm{X} 3$ & 0.02774 & $<7$ & {$[7-9)$} & {$[9-11)$} & {$[11-13)$} & $>13$ \\
\hline & $\mathrm{X} 4$ & 0.01536 & $<1.49$ & {$[1.49-1.52)$} & {$[1.52-1.55)$} & {$[1.55-1.57)$} & $>1.57$ \\
\hline & $\mathrm{X} 5$ & 0.03156 & $<0$ & {$[0--5)$} & {$[-5-5)$} & {$[5-15)$} & $>15$ \\
\hline & $\mathrm{X} 6$ & 0.08370 & $<1200$ & {$[1200-1500)$} & {$[1500-1700)$} & {$[1700-1900)$} & $>1900$ \\
\hline & $\mathrm{X} 7$ & 0.03854 & $<5000$ & {$[5000-10000)$} & [10000-20000) & {$[20000-30000)$} & $>30000$ \\
\hline & $\mathrm{X} 8$ & 0.02012 & $>85$ & {$[70-85)$} & {$[50-70)$} & {$[30-50)$} & $<30$ \\
\hline & X9 & 0.02958 & $<2000$ & {$[2000-4000)$} & {$[4000-6000)$} & {$[6000-8000)$} & $>8000$ \\
\hline & $\mathrm{X} 10$ & 0.01491 & $<100$ & {$[100-130)$} & {$[130-170)$} & {$[200-250)$} & $>250$ \\
\hline & $\mathrm{X} 13$ & 0.01975 & $<1000$ & {$[1000-1500)$} & {$[1500-2000)$} & {$[2000-2500)$} & $>2500$ \\
\hline & $\mathrm{X} 14$ & 0.01776 & $<200$ & {$[200-400)$} & {$[400-600)$} & {$[600-800)$} & $>800$ \\
\hline & $\mathrm{X} 15$ & 0.01650 & $<1000$ & {$[1000-3000)$} & {$[3000-5000)$} & {$[5000-7000)$} & $>7000$ \\
\hline & $\mathrm{X} 16$ & 0.01583 & $<2000$ & {$[2000-3000)$} & {$[3000-4000)$} & {$[4000-5000)$} & $>5000$ \\
\hline & $\mathrm{X} 18$ & 0.01124 & $<1000$ & {$[1000-3000)$} & {$[3000-5000)$} & {$[5000-7000)$} & $>7000$ \\
\hline & X19 & 0.02201 & $0-5000$ & [5000-8000) & {$[8000-10000)$} & {$[10000-15000)$} & $>15000$ \\
\hline \multirow{11}{*}{ State layer } & $\mathrm{Y} 1$ & 0.02469 & $>37.35$ & {$[29.05-37.35)$} & {$[20.75-29.05)$} & {$[12.45-20.75)$} & $<12.45$ \\
\hline & $\mathrm{Y} 2$ & 0.01208 & $>298.2$ & [298.0-298.2) & {$[297.3-298.0)$} & {$[297.0-297.3)$} & $<297.0$ \\
\hline & Y3 & 0.02005 & $<30$ & {$[30-120)$} & {$[120-200)$} & {$[200-250)$} & $>250$ \\
\hline & Y4 & 0.11547 & $<500$ & {$[500-1000)$} & {$[1000-1500)$} & {$[1500-2500)$} & $>2500$ \\
\hline & Y5 & 0.08186 & $<500$ & {$[500-1000)$} & [1000-1500) & {$[1500-2500)$} & $>2500$ \\
\hline & Y6 & 0.02514 & $>2000$ & {$[1500-2000)$} & [1000-1500) & {$[500-1000)$} & $<500$ \\
\hline & Y7 & 0.01052 & $<10$ & [10-12) & [12-14) & [14-16) & $>16$ \\
\hline & Y8 & 0.04587 & $>255$ & [219-255) & [146-219) & {$[73-146)$} & $<73$ \\
\hline & Y9 & 0.01478 & $>50$ & {$[40-50)$} & {$[30-40)$} & {$[20-30)$} & $<20$ \\
\hline & Y10 & 0.02382 & $>90$ & [90-80) & [80-60) & [60-35) & $<35$ \\
\hline & Y11 & 0.02450 & $>90$ & {$[90-80)$} & {$[80-60)$} & {$[60-35)$} & $<35$ \\
\hline \multirow{5}{*}{ Control layer } & $\mathrm{Z1}$ & 0.01834 & $>80$ & {$[60-80)$} & {$[40-60)$} & [20-40) & $<20$ \\
\hline & $\mathrm{Z2}$ & 0.10272 & $>40$ & {$[30-40)$} & {$[20-30)$} & {$[10-20)$} & $<10$ \\
\hline & $\mathrm{Z3}$ & 0.01287 & $>10000$ & {$[8000-10000)$} & {$[5000-8000)$} & [2000-5000) & $<2000$ \\
\hline & $\mathrm{Z4}$ & 0.04616 & $>500$ & [400-300) & {$[300-200)$} & {$[100-50)$} & $<50$ \\
\hline & $\mathrm{Z5}$ & 0.01790 & $>500$ & {$[300-500)$} & {$[100-300)$} & {$[50-100)$} & $<50$ \\
\hline
\end{tabular}

From Table 10 we can see that all of the indexes in the control layer are at the sensitive level: $\mathrm{Z} 2$ shows a negative development trend, and Z1, Z3, and Z4 show a positive development trend. In 2005 the Z3 was at a middle warning level and the development trend turned into an early warning status, becoming strong in 2014; Z1, and Z4 were in heavy warning in 2005 and turned into light warning in 2014; Z2 was in heavy warning in 2005 and turned into middle warning in 2014; however, development exhibits a negative trend in future development; Z5 was in heavy warning in 2005 and turned into middle warning in 2014.

Referenced by the ideas short board effect, this paper makes the light and heavy warning factors limiting ecosecurity factors, and they are named as the 'key warning sources' in the pressure layer in 2005, X3, X8, X15, Y1, $\mathrm{Y} 5, \mathrm{Y} 9, \mathrm{Z1}, \mathrm{Z} 2, \mathrm{Z} 4$, and Z5 are the 'key warning sources' in 2014, and the key warning source indexes are X3, X5, $\mathrm{X} 7, \mathrm{X} 9, \mathrm{X} 10, \mathrm{X} 16, \mathrm{X} 18, \mathrm{X} 19, \mathrm{Y} 4, \mathrm{Y} 9, \mathrm{Z1}$, and Z4 are the main pressure factors; the key warning source indexes increased. In 2014, X8 and X15 were not the limiting factors, newly increased were X9, X16, X18, and X19. In the state layer, Y5 was not a limiting factor, Y4 became the limiting factor, and $Y 9$ was always a limiting factor. In the control layer, Z2 and Z5 were not the limiting factors, and $\mathrm{Z} 4$ is still a limiting factor.

\section{Discussion and Conclusions}

At present, eco-security early warning research is in the exploration stage (You, 2014), and eco-security early warning research about mountains is very limited; 
Table 6. Ecological security early warning analysis results from 2005-14.

\begin{tabular}{|c|c|c|c|c|c|}
\hline year & NW & FW & MW & LW & HW \\
\hline 2005 & -2.1022 & -0.5907 & -0.4783 & -0.4575 & $\mathbf{- 0 . 4 0 3 0}$ \\
\hline 2006 & -2.1081 & -0.6526 & -0.5732 & $\mathbf{- 0 . 4 3 3 2}$ & -0.4608 \\
\hline 2007 & -2.3132 & -0.6826 & -0.5097 & -0.4302 & $\mathbf{- 0 . 4 2 3 1}$ \\
\hline 2008 & -3.7864 & $\mathbf{- 0 . 4 8 8 1}$ & -2.6374 & -2.9862 & -5.3289 \\
\hline 2009 & -0.8596 & -0.0866 & $\mathbf{- 0 . 0 0 7 6}$ & -0.7534 & -1.0484 \\
\hline 2010 & -2.6112 & $\mathbf{- 0 . 4 1 7 5}$ & -0.7836 & -0.5418 & -0.4366 \\
\hline 2011 & $-\mathbf{0 . 3 4 2 6}$ & -10.3239 & -12.4915 & -16.2250 & -47.3636 \\
\hline 2012 & -3.5475 & $\mathbf{- 0 . 6 9 2 3}$ & -1.7505 & -1.8674 & -4.1303 \\
\hline 2013 & -2.8849 & -0.9264 & $\mathbf{- 0 . 4 8 1 9}$ & -0.6071 & -0.6660 \\
\hline 2014 & -0.3202 & -0.3511 & -0.2345 & $\mathbf{- 0 . 0 1 7 5}$ & -0.3070 \\
\hline
\end{tabular}

The bold fonts mean that the early warning prediction trends are consistent with the actual situation.

therefore, the significance of this study is to further enrich the eco-security early warning research theory, to improve the ecological security research methods, and to provide results that give practical and significant guidance.

1. This research evaluated the plateau mountain ecological security early warning system, constructing an index system based on the P-S-R conceptual model. In an attempt to fully overcome subjective influences, the Granger causality test was applied to further implement the targeted and objective index system selection, thereby achieving one-to-one analysis of the results and factors and further enriching the theoretical research of eco-security early warning.

2. In terms of practical significance, the author uses the Kizilsu Kirghiz Autonomous Prefecture as the research object and applies the eco-security early warning analysis; the study obtained results of the ecosecurity change situation and projections for future development in the study area. The results for the

Table 7. Percentage of indicators for a sensitive warning rank in the early warning system $(\%)$.

\begin{tabular}{|c|c|c|c|}
\hline Year & Pressure & State & Control \\
\hline 2005 & 19.35 & 16.13 & 16.13 \\
\hline 2006 & 16.13 & 12.90 & 16.13 \\
\hline 2007 & 25.8 & 16.13 & 16.13 \\
\hline 2008 & 25.8 & 16.13 & 16.13 \\
\hline 2009 & 25.8 & 16.13 & 16.13 \\
\hline 2010 & 32.26 & 16.13 & 12.90 \\
\hline 2011 & 22.58 & 12.90 & 9.68 \\
\hline 2012 & 35.48 & 19.35 & 12.9 \\
\hline 2013 & 12.9 & 16.13 & 9.68 \\
\hline 2014 & 38.7 & 19.35 & 16.13 \\
\hline
\end{tabular}

study area have scientific significance for future ecosecurity construction:

a) The eco-security situation across the whole study area is gradually developing in a positive direction, but due to ecological impacts, it is very serious in this decade, and the current eco-security situation is still in a state of light warning. The overall eco-security level is low, but it is still facing great pressure, and the internal ecological safety risk in the study area still cannot be ignored.

b) The eco-security pressure in 2014 was the greatest, and the eco-security status exhibited an increasing trend of warning source indexes; from the control layer, the study area exhibits gradual attention being paid to the construction of eco-security in ecological management, education, artificial afforestation, etc. from 2005-14. However, the overall eco-security level is low, and the whole eco-security management capacity is insufficient; the study area still needs to increase the intensity of ecological safety regulations and to rapidly promote eco-security regulation capacity.

c) Through the comparative analysis in 2005 and 2014, the author found that the natural population growth rate, total water use growth rate per year, water consumption per capita, plastic mulch recovery rate, wood harvesting, and the amount of chemical fertilizer usage were always the warning source indexes; therefore, the study area should attach importance to these several aspects in the study area, implement specific measures for each problem, and reduce the threat to eco-security. There are newly increasing warning source indicators, namely construction land area, industry power consumption, agricultural power consumption, industrial wastewater emissions, industrial soot emissions and solid waste emissions, and these indicate that the industrial and agricultural development level gradually improved over nearly a decade in the study area. Even though the newly 


\begin{tabular}{|c|c|c|c|c|c|c|}
\hline$\frac{\partial}{\bar{x}}$ & $\Xi$ & $\left|\begin{array}{l}\vec{n} \\
\vdots \\
0 \\
\dot{0}\end{array}\right|$ & $>$ & $\left|\begin{array}{c}0 \\
\infty \\
\widetilde{0} \\
0 \\
0\end{array}\right|$ & $\begin{array}{l}0 \\
1 \\
\propto\end{array}$ & + \\
\hline$\frac{\infty}{x}$ & $=$ & $\begin{array}{l}0 \\
\vdots \\
0 \\
0 \\
0 \\
0\end{array}$ & $>$ & $\mid \begin{array}{c} \pm \\
0 \\
0 \\
0 \\
0 \\
0\end{array}$ & $\begin{array}{l}0 \\
\stackrel{1}{1} \\
\alpha\end{array}$ & + \\
\hline$\frac{0}{x}$ & $=$ & $\begin{array}{l}\hat{n} \\
\hat{\delta} \\
\dot{0}\end{array}$ & $>$ & 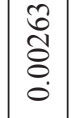 & $\begin{array}{l}0 \\
\stackrel{1}{1} \\
\alpha\end{array}$ & + \\
\hline$\frac{n}{x}$ & $>$ & $\left|\begin{array}{l}\stackrel{a}{\hat{\sigma}} \\
\vdots \\
\dot{0}\end{array}\right|$ & $\Xi$ & 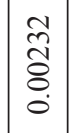 & $\stackrel{n}{\lambda}$ & + \\
\hline$\stackrel{\vec{x}}{\star}$ & - & $\left|\begin{array}{l}\overrightarrow{\hat{o}} \\
\dot{0} \\
\dot{0}\end{array}\right|$ & $=$ & $\begin{array}{l}0 \\
0 \\
8 \\
0 \\
0\end{array} \mid$ & $\vec{i}$ & \\
\hline$\frac{\tilde{x}}{x}$ & - & $\left|\begin{array}{l}\infty \\
0 \\
0 \\
0 \\
0\end{array}\right|$ & - & 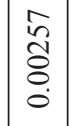 & خ & \\
\hline$\stackrel{\ominus}{\star}$ & - & 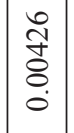 & $\geq$ & $\left|\begin{array}{c}\overrightarrow{8} \\
\vdots \\
0 \\
\dot{1}\end{array}\right|$ & $\overrightarrow{0}$ & + \\
\hline$\ddot{x}$ & - & $\left|\begin{array}{l}\vec{t} \\
\dot{0} \\
\vdots \\
0\end{array}\right|$ & $\geq$ & $\left|\begin{array}{l}0 \\
0 \\
0 \\
0 \\
0 \\
1\end{array}\right|$ & 잉 & \\
\hline$\underset{\varkappa}{\rtimes}$ & $>$ & $\begin{array}{c}\vec{n} \\
o \\
0 \\
i\end{array}$ & $\exists$ & $\left|\begin{array}{l}t \\
0 \\
\tilde{o} \\
0 \\
0\end{array}\right|$ & $\begin{array}{l}0 \\
\lambda \\
\lambda\end{array}$ & \\
\hline $\bar{x}$ & - & $\left|\begin{array}{l}\tilde{b} \\
\tilde{n} \\
0 \\
0 \\
0\end{array}\right|$ & $\geq$ & $\begin{array}{c}0 \\
0 \\
0 \\
0 \\
0 \\
0 \\
1\end{array}$ & 임 & \\
\hline$\succsim$ & $\Xi$ & 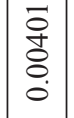 & $\exists$ & 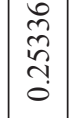 & $\begin{array}{l}0 \\
\lambda \\
\lambda\end{array}$ & \\
\hline 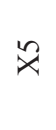 & $\exists$ & $\mid \begin{array}{l}0 \\
0 \\
0 \\
\tilde{o} \\
0 \\
0\end{array}$ & $\geq$ & $\left|\begin{array}{c}\overrightarrow{0} \\
\dot{0} \\
\dot{1} \\
\dot{1}\end{array}\right|$ & 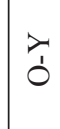 & + \\
\hline 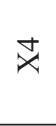 & - & $\begin{array}{l}\stackrel{\partial}{\widehat{े}} \\
\grave{\delta} \\
\dot{0}\end{array}$ & $\exists$ & 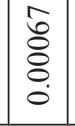 & t) & + \\
\hline$\tilde{\varkappa}$ & $>$ & 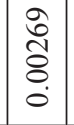 & $>$ & $\left|\begin{array}{l}0 \\
0 \\
0 \\
0 \\
0\end{array}\right|$ & $\stackrel{m}{\lambda}$ & + \\
\hline $\bar{x}$ & - & $\left|\begin{array}{l}\overrightarrow{8} \\
\dot{0} \\
\dot{0}\end{array}\right|$ & - & 0 & U. & + \\
\hline 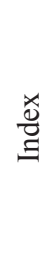 & 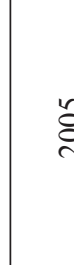 & : & $\stackrel{\square}{\square}$ & ¿ & 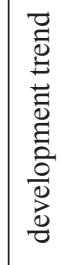 & 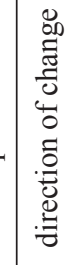 \\
\hline
\end{tabular}

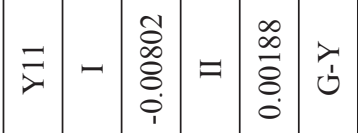

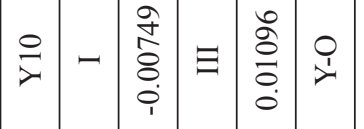

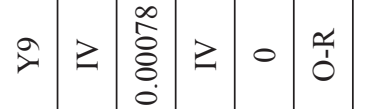

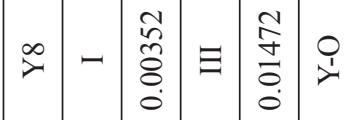

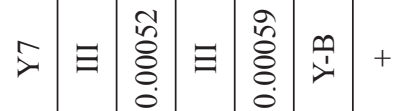

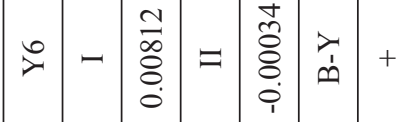

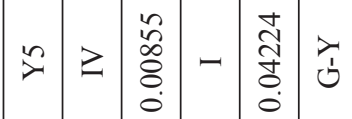

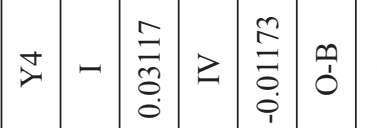

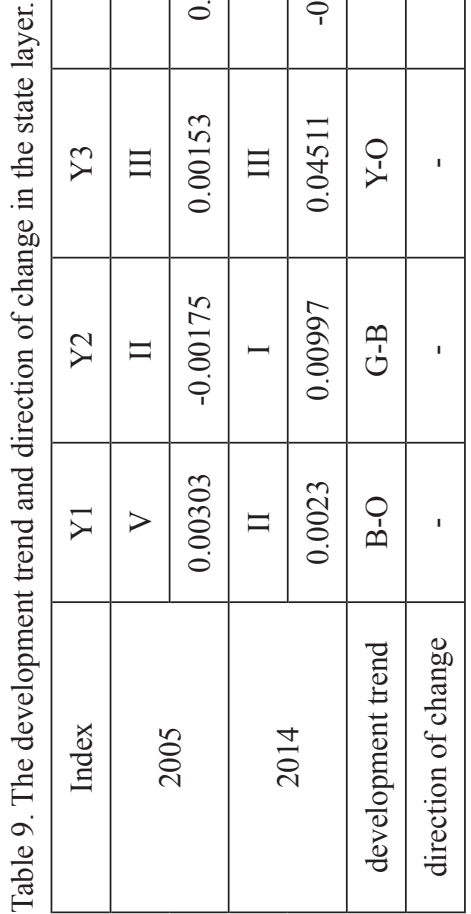

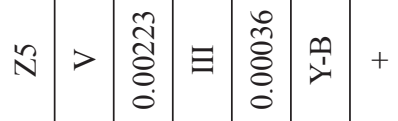

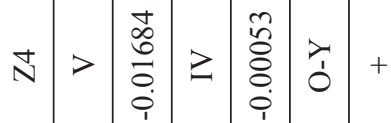

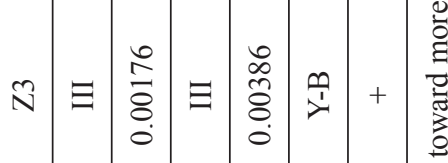

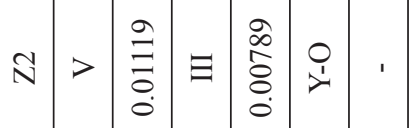

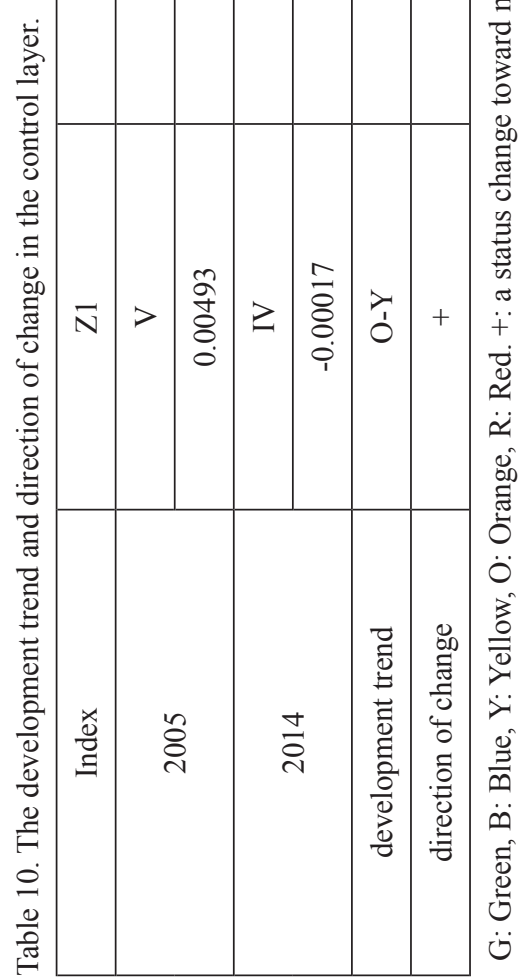


increasing warning source index gradually developed in a positive direction, the study area belongs to an ecologically fragile area, therefore the threat to ecosecurity cannot be ignored. From the state layer, the warning source indexes indicated an increasing trend from 2005-14, the eco-security situation was not ideal; therefore, the study area needs to find a way toward a sustainable development compromise between industrial and agricultural development and eco-security, and the study area needs to increase the science, technology, and fund investments in pollution control and treatment, accelerate the positive transformation of the warning source indexes, and improve eco-security.

d) Through the key warning source index analysis, the key warning source indexes in the study area newly increased issues of total water use growth rate per year, industry power consumption, agricultural power consumption, industrial waste water emissions, industrial soot emissions, solid waste emissions, the amount of chemical fertilizer usage, and the current ecological security pressure in the study area were mainly derived from industrial and agricultural development. The key warning source indexes in the state layer and control layer have tapered off, but the overall ecological security situation in the study area is not ideal; we could infer that the threat of key warning source factors for eco-security are very obvious in the study area, the study area faces high ecological pressure. Although the control intensity has gradually increased, the control effect is not obvious for ecosecurity, and the contradiction between eco-security and social economic development is still obvious and needs to draw attention in the study area.

e) An earthquake in a typical mountainous area has an influence on the eco-security and cannot be neglected [40, 61-63]. The study area is a typical seismic region, according to the author's statistical analysis, indicating that a total of 11 earthquakes of grade 5 or above occurred in the study area over 10 years; the results indicate that the study area gradually increased the financial input in the governance of natural geological disasters, and the future development trend is positive; however, a geological disaster is uncertain, and due to the high frequency of earthquakes in the study area, the study area still needs to increase investment in the governance of natural geological disasters in the study area.

Although the research has included a beneficial analysis of the eco-security early warning research, there are still some problems in the actual research that require further perfection and study:

1. Ecological security involves dynamic change, although the study analyzed continuous dynamic changes over nearly 10 years in the study area, the research still cannot avoid the contradiction of dynamic data acquisition. The main obstacle is that many ecological process data from the large-scale monitoring and longterm experiments are very difficult to obtain.
2. The eco-security early warning research was still in the exploration stage, each type of study area has respective characteristics, and current research on early warning systems has no standard or mature theory and methods; the study still could not establish a perfect ecological index system for plateau-mountain eco-security and could not perform an accurate classification for the index grade. These aspects make it difficult to avoid imperfections, and further research is required.

\section{Acknowledgements}

This paper was completed with the support of the Western PhD Project of the Chinese Academy of Sciences (XBBS201210), the National Natural Science Foundation (No. 41301163), and the Chinese Academy of Sciences Visiting Professorship for Senior International Scientists (No. 2015VEA048).

\section{References}

1. ZHAO Y.Z., ZOU X.Y., CHENG H., JIA H.K., WU Y.Q., WANG G.Y., ZHANG C.L., GAO S.Y. Assessing the ecological security of the Tibetan plateau: Methodology and a case study for Lhaze County. Journal of Environmental Management, 80, 120-131, 2006.

2. LENTON T.M.What early warning systems are there for environmental shocks? Environmental science \& policy, 27, 60-75, 2013.

3. MARVIN H.J.P., KLETER G. A., VAN DER FELS-KLERX H.J., NOORDAM M.Y., FRANZ E., WILLEMS D.J.M., BOXALLA. Proactive systems for early warning of potential impacts of natural disasters on food safety: Climate-changeinduced extreme events as case in point. Food Control, 34 (2), 444, 2013.

4. GASPARINI P., MANFREDI G., ZSCHAU J. Earthquake early warning as a tool for improving society's resilience and crisis response. Soil Dynamic sand Earthquake Engineering, 31, 267, 2011.

5. INTRIERI E., GIGLI G., MUGNAI F., FANTI R., CASAGLI N. Design and implementation of a landslide early warning system. Engineering Geology, 147, 124, 2012.

6. HANDMER J. Improving flood warnings in Europe: a research and policy agenda. Global Environmental Change Part B: Environmental Hazards. 3 (1), 19, 2001.

7. FAKHRUDDIN S.H.M., KAWASAKI A., BABEL M.S. Community responses to flood early warning system: Case study in Kaijuri Union, Bangladesh. International Journal of Disaster Risk Reduction, doi:10.1016/j.ijdrr.2015.08.004, 2015.

8. CAlVello M., ORSI R.N., PICIUllO L., Paes N., Magalhaes M., Lacerda W. A.,The Rio de Janeiro early warning system for rainfall-induced landslides: Analysis of performance for the years 2010-2013. 12, 3, 2015.

9. SIDDIGA A. A.H., ELLISON A. M. , OCHS A., VILLARLEEMAN C., LAU M. K. How do ecologists select and use indicator species to monitor ecological change? Insights from 14 years of publication in Ecological Indicators. Ecological Indicators, 60, 223, 2016.

10. ZURLINI G., JONES K.B., RIITTERS K.H., LI B.L., PETROSILLO I.Early warning signals of regime shifts from cross-scale connectivity ofland-cover patterns. Ecological 
Indicators, 45, 549, 2014.

11. MUSCOLO A., SETTINERI G., ATTINÀE. Early warning indicators of changes in soil ecosystem functioning. Ecological Indicators, 48, 542, 2015.

12. WOUTERS N., SERAFIM M.P., VALAYER P.J., KIRKUP B.C., WANG Y.J., CABRAL H.N.Early warning signals as indicators of cyclostationarity inthree-species hierarchies. Ecological Indicators, 60, 586, 2016.

13. ZHOU B., ZHONG L.S, CHEN T., ZHOU R. Ecological security early-waining in Zhoushan Islands based on Variable weight model. Chinese Journal of Applied Ecology, 26, 1854, 2015

14. LI Y.F, SUN X., ZHU X.D, CAO H.H. An early warning method of landscape ecological security in rapid urbanizing coastal areas and its application in Xiamen, China. Ecological Modelling, 221, 2251, 2010.

15. YOU W.B, HE D.J, QIN D.H, JI Z.R, WU L.Y., YU J.A., CHEN B.R., TAN Y. System construction of early warning for ecological security at cultural and natural heritage mixed sites and its application: A case study of Wuyishan Scenery District.Chinese Journal of Applied Ecology, 25, 1455, 2014.

16. ZHAO H.B,MA Y.J.Study on early-warning model based on variable weight-matter element analysis for ecological security in old industrial bases: a case study of Jilin Provience.Acta Ecological Sinica, 34 (16), 4720, 2014.

17. GONG J.Z, LIU Y.S, XIA B.C, ZHAO G.W. Urban ecological security assessment and forecasting, based on a cellular automata model: A case study of Guangzhou, China. Ecological Modelling, 220, 3612, 2009.

18. XU S.W, LI G.Q, LI Z.M.China agricultural outlook for 2015-2024 based on China Agricultural Monitoring and Early-warning System (CAMES). Journal of Integrative Agriculture, 14 (9), 1889, 2015.

19. LIU D., CHANG Q.Ecological security research progress in China. Acta Ecologica Sinica, 35, 111, 2015.

20. LI X.B, TIAN M.R,WANG H., WANG H., YU J.J. Development of an ecological security evaluation methodbased on the ecological footprint and applicationto a typical steppe region in China. Ecological Indicators, 39, $153,2014$.

21. LINDE E.V., DUIN P.V.The Delphi method as early warning Linking global societal trends to future radicalization and terrorism in The Netherlands. Technological Forecasting \& Social Change, 78, 1557, 2011.

22. IMEN S., CHANG N.B, YANG Y. J. Developing the remote sensing-based early warning system for monitoring TSS concentrations in Lake Mead. Journal of Environmental Management, 160 (1),73, 2015.

23. LU X.C., ZHANG J.Q., LI X.Z. Geographical information system-based assessment of ecological security in Changbai Mountain region. Journal Of Mountain Science, 11 (1), 86, 2014.

24. WANG H.M, WANG H.E, SUN H.Y, WANG X.L, LIAO X.Y, CHEN Z.J, LI X.W. Assessment of the Ecological Security in the Three Gorges Reservoir Area by Using the Ecological Footprint Method. Journal of Mountain Science, 9 (6), 891, 2012.

25. CAI W. The matter-element model and application. Science and technology literature press, China, 1994.

26. PAN G.B, XU Y.P, YU Z.H, SONG S., ZHANG Y. Analysis of river health variation under the background of urbanization based on entropy weight and matter-element model:A case study in Huzhou City in theYangtze River Delta,China. Environmental Research, 139, 31, 2015.

27. DENG X.J, XU Y.P, HAN L.F, YU Z.H, YANG M.N, PAN G.B. Assessment of river health based on an improved entropy-based fuzzymatter-element model in the Taihu Plain, China. Ecological Indicators, 57, 85, 2015.

28. JIA Y.H, ZHAO J., NAN Z.R, ZHAO C.Y., WANG S.L. Ecological safety assessment of grassland based on entropyright method:A case study of Gansu pastoral area.Chinese Journal of Ecology, 25 (8), 1003, 2006.

29. JOLLANDSA N., LERMIT J., PATTERSON M. Aggregate eco-efficiency indices for New Zealand - a principal components analysis. Journal of Environmental Management, 73 (4), 293, 2004.

30. ORELLANA A.C., CABEZ M.D. Local ecological footprint using Principal Component Analysis: A case study of localities in Andalusia (Spain). Ecological Indicators, 57, 573, 2015.

31. PUIG M.G., RIVERO S.S. Granger-causality in peripheral EMU public debt markets: A dynamic approach. Journal of Banking \& Finance, 37, 4627, 2013.

32. SYSOEV I.V., SYSOEVA M.V. Detecting changes in coupling with Granger causality method from time series with fast transient processes. Physica D, 309, 9, 2015.

33. YU L., LI J.J, TANG L., WANG S. Linear and nonlinear Granger causality investigation between carbon market and crude oil market: A multi-scale approach. Energy Economics, 51, 300, 2015.

34. LI H.Q, ZHONG W.L, PARK S.Y. Generalized crossspectral test for nonlinear Granger causality with applications to money-output and price-volume relations. Economic Modeling, http://dx.doi.org/10.1016/j. econmod.2015.09.037, 2015.

35. ZHONG X.H. Study of Protection and Construction of Mountain Ecological Security Barrier in China. Journal of Mountain Science, 26 (1), 2, 2008.

36. GARDNER J. S., DEKENS J. Mountain hazards and the resilience of social-ecological systems: lessons learned in India and Canada. Nat Hazards, 41 (2), 317, 2007.

37. PENG J., DU Y.Y, LIU Y.X, HU X.X. How to assess urban development potential in mountain areas?An approach of ecological carrying capacity in the view of coupled human and natural systems. Ecological Indicators, 60, 1017, 2016.

38. LEPUSCHITZ E. Geographic information systems in mountain risk and disaster management. Applied Geography, 63, 212, 2015.

39. BIGIO E.R., SWETNAM T.W., BAISAN C.H. Local-scale and regional climate controls on historical fire regimes in the San Juan Mountains, Colorado. Forest Ecology and Management, 360, 311, 2016.

40. WU N., LU T., LUO P., ZHU D. A review of the impacts of earthquake on mountain ecosystems: taking 5.12 Wenchuan Earthquake as an example. Acta Ecologica Sinica, 28 (12), 5810, 2008.

41. RUEFF H., RAHIM I., KOHLER T., MAHAT T.J., ARIZAE C. Can the green economy enhance sustainable mountain development? The potential role of awareness building. Environmental science \& policy, 49, 85, 2015.

42. KOO K.A., MADDEN M., PATTEN B.C. Projection of red spruce (Picea rubens Sargent) habitat suitability and distribution in the Southern Appalachian Mountains, USA. Ecological Modelling, 293, 91, 2014.

43. YAO Z.Y, ZHAO C.Y., YANG K.S., LIU W.C., LI Y., YOU J.D., XIAO J.H. Alpine grassland degradation in the Qilian Mountains, China -A case study in Damaying Grassland. Catena, 137, 494, 2016.

44. PASOLLI L., ASAM S., CASTELLI M., BRUZZONE L., WOHLFAHRT G., ZEBISCH M., NOTARNICOLA C. Retrieval of Leaf Area Index in mountain grasslands in the Alps from MODIS satellite imagery. Remote Sensing of 
Environment, 165, 159, 2015.

45. MENGA R., DENNISON P.E., HUANG C.Q., MORITZ M.A., ANTONIO C.D. Effects of fire severity and postfire climate on short-term vegetation recovery of mixedconifer and red fir forests in the Sierra Nevada Mountains of California. Remote Sensing of Environment, 171, 311, 2015.

46. FLATLEY W.T., LAFON C.W., GRISSINO-MAYER H.D., LAFOREST L.B. Changing fire regimes and old-growth forest succession along a topographic gradient in the Great Smoky Mountains. Forest Ecology and Management, 350, 96, 2015.

47. PIELECH R., ANIOŁ-KWIATKOWSK J., SZCZEŚSIAK E. Landscape-scale factors driving plant species composition in mountain streamside and spring riparian forests. Forest Ecology and Management, 347, 217, 2015.

48. OKEA O.A., THOMPSON K.A. Distribution models for mountain plant species: The value of elevation. Ecological Modelling, 301, 72, 2015.

49. WANG Z.H., YIN X.Q., LI X.Q. Soil mesofauna effects on litter decomposition in the coniferous forest of the Changbai Mountains, China. Applied Soil Ecology, 92, 64, 2015.

50. TUERDI P. Kizilsu Kirghiz Autonomous Prefecture Overview. Nationalities Publishing House, Xinjiang,China. 2009.

51. HAN B.L., LIU H.X., WANG R.S. Urban ecological security assessment for cities in the Beijing-Tianjin-Hebei metropolitan regionbased on fuzzy andentropy methods. Ecological Modelling, 318, 217, 2015.

52. NI X.J., NAN Y., ZHU W.H, LIU G.M., LIU C., YAO K. Study on comprehensive assessment of ecological security in Changbai Mountain Region based on multi-hazard natural disasters risk. Geographical Research, 33 (7), 1348, 2014.
53. LI W., LIU Y.J, YANG Z.F. Preliminary Strategic Environmental Assessment of the Great Western Development Strategy: Safeguarding Ecological Security for a New Western China. Environmental Management, 49, 483, 2012.

54. WU K.Y., HU S.H., SUN S.Q. Application Of Fuzzy Optimization Model In Ecological Security Pre-Warning. Chinese Geographical Science, 15 (1), 29, 2005.

55. GRANGER C.W.J. Investigating causal realations by econometric models and cross-spectral methods. Econometrica, 37 (3), 424, 1969.

56. TAO Y., JOE Q. Root cause diagnosis of plant-wide oscillations using Granger causality. Journal of Process Control, 24 (2), 450, 2014.

57. ZADEH L.A. Fuzzy Sets. Iformation and Control, 8, 338, 1965.

58. WANG J.F, LU Z.D. The determine method of membership fuction in fuzzy control.Henan Science, 18 (4), 348, 2000.

59. GLEICK J. The information: a history, a theory, a flood. Posts and Telecom Press, China, 2013.

60. LUDOVISI A. Effectiveness of entropy-based functions in the analysis of ecosystem state and development. Ecological Indicators, 36, 617, 2014.

61. HALVOMAN S.J., HAMILTON J.P. Vulnerability and the Erosion of Seismic Culture in Mountainous Central Asia. Mountain Research and Development, 27 (4), 322, 2007.

62. GARWOOD N.C., JANOS D. P., BROKAW N. Earthquakecaused landslides: a major disturbance to tropical forests. Science, 205, 997, 1979.

63. JOHNS R.J. The instability ofthe tropical ecosystem in New Guinea. Blumea, 31, 341, 1986. 